\title{
Documentation Studies at the University of Tromsø: A new way to educate librarians?
}

\author{
Roswitha Skare \\ Department of Language and Culture, University of Troms $\phi$ The Arctic University of Norway, Postboks \\ 6050, NO-9037 Troms $\phi$, Norway \\ Tel.: +47 77646318; E-mail: Roswitha.Skare@uit.no
}

\begin{abstract}
The article presents an overview of the history of Documentation Studies at the University of Troms $\varnothing$ in Norway, a study programme founded in 1996. The article starts with a brief historical background to the degree's foundation before the main ideas behind the choice of the concept are described. The last part of the article is devoted to the alterations made to the programme over the last 15 years in response to changes in the Norwegian education system and in a constant attempt to better equip the programme and its students to deal with broader shifts in society.
\end{abstract}

Keywords: Document, documentation, study programme, librarian, Norway, University of Troms $\emptyset$

\section{Introduction}

Documentation Studies was established at the University of Troms $\varnothing$ in Norway in 1996. At 22 years, the degree programme is still young. Nevertheless, there have been many changes over the years. This article starts by giving a brief historical background to the degree's foundation in 1996 before moving on to describe the main ideas behind the choice of the concept. The last part of the article is devoted to the alterations made to the programme over the last 15 years in response to changes in the Norwegian education system and in a constant attempt to better equip the programme and its students to deal with broader shifts in society.

Documentation Studies in Norway celebrated both its $10^{\text {th }}$ and its $20^{\text {th }}$ anniversary with international publications. In 2007, an anthology was published with the title $A$ Document (Re)turn. Contributions from a Research Field in Transition (Skare et al., 2007 ) to celebrate the $10^{\text {th }}$ anniversary; in 2016 a special issue of the Proceedings from the Document Academy was published for the $20^{\text {th }}$ anniversary with the title Neo-documentation Around the World: Rethinking Boundaries. Both publications include papers by Niels W. Lund, the founder of Documentation Studies in Troms $\emptyset$. This article is based on Lund's accounts and tries to give an overview over the development of the last 22 years, focusing on the concept of Documentation Studies and its teaching.

\section{Historical background of the founding of Documentation Studies in 1996}

Due to a general lack of librarians in Northern Norway during the 1980s, a polit- 
ical process to establish a librarianship programme outside the existing one in Oslo, the capital of Norway, was set in motion. In 1988, a committee was established and in February 1989, the committee launched a proposal for a degree in Documentation Studies as the basic programme for educating librarians and archivists. In addition to Troms $\varnothing$, the proposals suggested founding such alternative programmes in Trondheim and in Mo i Rana, but in 1995 the decision was made to start in Tromsø in January 1996.

While the need for librarians in Northern Norway was an important reason for establishing the programme at the University of Troms $\varnothing$, the choice of the name and the content of the programme were the result of technological and political developments during the 1980s. The most important of these was of course the creation of World Wide Web by Tim Berners-Lee in 1989 and the subsequent increased production and use of digital documents, which little by little began to combine text with images and sound, creating multimedia documents. In response to these technological developments, Norway created a new act of legal deposit, The Norwegian Act of Legal Deposit of Generally Available Documents of 9 June 1989, which came into force on 1 July 1990. This act stated that "[a]ll material published in Norway must be legally deposited with the National Library of Norway. This applies regardless of the format of publication, as the law is media-neutral" (https://www.nb.no/en/legaldeposit/). As such, the law required that not only paper-based or printed documents be collected, but also photographs, films, broadcast material, and digital publications - both offline and online. This act, together with the newly established National Library, increased the need for an educational programme to deal with these new challenges.

Whereas comparable degree programmes at that time were called Library and Information Science, Niels W. Lund, the first full professor in Documentation Studies, ${ }^{1}$ decided to broaden the perspective by using the terms "document" and "documentation". As pointed out by Lund, the committee, which consisted of librarians and faculty members from different disciplines, had not "much knowledge of the documentation theorists $[\ldots]$. The choice of the name Documentation studies was not based on a paradigmatic critique of Library and Information Science, but on a much more pragmatic and general political interest in relation to the establishment of the National Library in Norway in 1989 and the closely related launching of a very broadly defined act of legal deposit in Norway [...]" (Lund, 2007, p. 12).

The name and the ideas behind it also had consequences for the courses' content, however, encouraging students to study not only paper-based, printed documents, but any document. Documents chosen by students could be fixed or fluid, alive or dead, and from any medium, very much in the tradition of the European documentalists from the beginning of the 20th century such as Paul Otlet and Suzanne Briet. It is worth mentioning that Lund was not aware of Otlet and Briet's work at that time.

\footnotetext{
${ }^{1}$ For an account of the first year of the study programme, see Lund (2016).
} 
Only after the Troms $\emptyset$ programme was established did Lund meet Michael Buckland and W. Boyd Rayward at a conference in Copenhagen in August 1996 and became familiar with their work and that of Otlet and Briet. One might argue that Niels W. Lund's idea of a broad practical and theoretical education for librarians was thus also in line with international developments during the late 1990s with researchers like Michael Buckland, W. Boyd Rayward, and Ron Day, who helped rejuvenate the concept of the document and documentation by publishing articles such as "What is a 'document'?" (Buckland, 1997) and translating French texts, introducing names like Otlet and Briet to an Anglo-American audience. Together with the practical challenges created by the new act of legal deposit, this provided the perfect justification for Documentation Studies.

Niels W. Lund was not only the mind behind the establishment of the education programme, he was also the first and for several years the only full professor. In 1998, one other permanent faculty member was appointed, and from the year 2000 onwards to the present, the faculty staff has included six permanent members. In the hiring process, Documentation Studies' complementary perspective ${ }^{2}$ was emphasised, and persons with qualifications from the humanities, social sciences as well as the natural sciences and technology were employed. The programme developed step by step, starting with an undergraduate programme consisting of seven semesters (see Lund, 2016 , p. 2 for details). A graduate of that programme would be eligible to apply for positions as head of a public library in Norway. When the first students had completed their undergraduate degrees, the Master's and Ph.D. programmes were initiated. In 2000, the first Master's student submitted his thesis on The Warburg Institute Library of cultural history (Søbstad, 2000).

Being a young and small discipline at the university, it was important for Documentation Studies to seek cooperation and support outside Troms $\varnothing$ and Norway. In 2003, the Document Academy (DOCAM) was established with annual conferences. ${ }^{3}$ Since 2014, the papers from that conference have been published in a peer-reviewed open access journal (https://ideaexchange.uakron.edu/docam/).

In 2005, a documentation summer school with scholars from several countries was organised in Troms $\varnothing$. The participation of members of a large and complex French document research programme led by Roger Pédauque, the Pluridisciplinary Thematic Network on Documents and Content: Creation, Indexing, Navigation (Réseau

\footnotetext{
${ }^{2}$ Niels W. Lund introduced the concept of complementarity based on the Danish physicist Niels Bohr (1885-1962), who had first formulated it as a basic principle of quantum theory in 1927. It refers to effects such as wave-particle duality, in which different measurements of a system reveal it to have either particle-like or wave-like properties. Both properties are necessary to gain complete knowledge of the phenomenon in question; they are complementary to one another but at the same time also exclude each other. In an article titled "Documentation in a Complementary Perspective", Lund (2004: 95) introduced the notion of complementarity as a central concept in documentation analysis. For a discussion of the concept, see also Skare (2009).

${ }^{3}$ See http://documentacademy.org/?annual-meetings. See also Lund and Buckland (2008).
} 
Thématique Pluridisciplinaire "Document et Contenu: Création, Indexation, Navigation" (RTP-Doc)), played an important role in connecting scholars from the AngloAmerican tradition with the research carried out by French academics.

\section{The main ideas behind the choice of the documentation concept}

The decision to call the degree programme Documentation Studies and not something with library and information as many would have expected, was a very conscious choice by Niels W. Lund. On the one hand, he was building on the tradition of the European documentalists, also considering three-dimensional objects or living animals to be documents. On the other hand, Lund's concept can also be understood as a reaction to what was usual in many disciplines in the humanities, such as literary studies or art history, where scholars used the concept of 'text' for all kinds of manifestations from printed books to films, video games and paintings. Very often they only focused on the object's meaning, ignoring or neglecting its materiality - or, in Lund's words: "the inferior status of the notion of physicality within the hermeneutic and semiotic tradition being defined as a physical vehicle or embodiment of the whole text" (Lund, 2010, p. 740).

By going back to the term's Latin origin, Lund argues that documentum "can be separated into the verb doceo and the suffix mentum" (Lund, 2010, p. 740). Based on the etymological roots and the conceptual history of the word 'document', Lund defines it as "any results of human effort to tell, instruct, demonstrate, teach or produce a play, in short to document, by using some means in some ways" (Lund, 2010, p. 743). Based on this definition, Lund developed his theory of documents and documentation based on the following main ideas:

- the meaning and materiality of a document are considered equally important and the relationship between materiality and meaning becomes an interesting subject of study;

- the focus on complementarity is a consequence of this, considering that a document has both material, mental and social aspects;

- it is interesting to investigate not only the finished products of the documentation process, like published novels or released films, but also the process itself and the choices the creator of a documents has to make. This becomes especially obvious when the students are supposed to produce their own documents;

- students can study not only documents that can be stored and retrieved, but also oral and more fluid documents like lectures, concerts, performances or web pages that get updated frequently;

- Documentation Studies deal with both a media and an institutional perspective, considering institutions like archives, libraries and museums to be document institutions.

Over the years, Niels W. Lund initiated and was part of several joint research projects where he combined these ideas and worked together with both practitioners and researchers in several fields. Examples of this collaboration include the world 
opera project, a networked performance of a distributed opera (see Geistweidt \& Lund, 2015), or his cooperation with researchers in computer science and medicine "to discuss how the concept of a document and documentation along with a general document model could inform us in the design and engineering of information or rather documentation systems" (Olsen et al., 2012, p. 100).

One important question discussed during the degree's first years was the question "What is a document?". While many other disciplines at the university start out by giving their first-year students one definition and only start to discuss the problems inherent in definitions later on, at Master's level, from their very first day Documentation Studies students were confronted with the fact that there are many possible definitions of the term document, depending on historical period and area of research. The students not only had to learn one or several definitions; they were encouraged to think critically and to find a definition that worked for their projects.

As mentioned above, the programme consisted of both practical and theoretical components to prepare the students for their future workplace. In the light of new technological developments and thus new problems to solve, Lund considered that " $[\mathrm{t}]$ he result of the training should hopefully be that students are aware of the complexity of documentation and that the document can never be completely isolated and considered to be essentially about one specific issue; instead, it must be viewed within a certain environment and how it has turned into a document analyzed" (Lund, 2007, p. 19). Students were encouraged to develop the ability to think on their own in order to solve problems. The way to achieve this was to make the students firstyear researchers, with their own research projects. Many later employers confirmed that our students were very well qualified to solve problems at their workplaces, not only having the practical tools required, but being able to think on their own, make decisions and find solutions.

These first years of Documentation Studies in Troms $\varnothing$ were thus characterised by student-driven activities, with students doing individual or collaborative projects with a large degree of freedom to choose what to study. The student cohort included both young people coming directly from secondary school and more mature learners coming from other educational backgrounds, such as teachers, musicians, cooks and so on. Many of the mature students combined their education and experiences with the new field of documentation. Depending on their chosen document and project, the students were also free to choose literature useful for the project, making their own reading lists. The first-year final exam then was a combination of written project paper and oral examination. Even though the free choice of projects led to a huge diversity of topics, Niels W. Lund identifies three main themes that were crucial for the students: "the selection of materials, means or media of documentation" (Lund, 2007, p. 19); "the human agent involved in the documentation process" (Lund, 2007, p. 20); "traditions for documentation in different fields" (Lund, 2007, p. 20). In addition to this, many of the projects had links to Troms $\emptyset$ and Northern Norway, were related to archives, libraries, and museums, were about text, images, film and threedimensional objects, and explored the possibilities offered by digital technology to 
produce multimedia reports combining traditional printed text with internet pages (see Lund, 2016, p. 10). The students were also encouraged to experiment and to create documents on their own, investigating the consequences of the choices they had made during the process.

In addition to more general and theoretical documentation studies, the students also had two semesters that focused on library studies. As with other similar degrees, the students spent part of their studies in libraries. But once again, there was one important difference: students from Troms $\emptyset$ were not only supposed to be trainees, they also had time to work on their own projects, chosen because of their interests and the type of library they were working in. These projects became the starting points for their exam essays.

\section{What has happened since?}

By the beginning of the new millennium, Documentation Studies had started to become institutionalised, with degree programmes at all levels (Bachelor's, Master's, and Ph.D.) and six permanent faculty members. Both national and international cooperation and research had been developed, and scholarly publications by documentoriented scholars could be found in a wide range of international journals.

But the times and thus also the education system and universities in Norway are changing. One of the most important changes occurred in 2003 when a national reform was implemented throughout Norway's entire higher education system. Norway was one of the first countries in Europe to implement the Bologna Declaration, thus creating a $3+2+3$-year system ${ }^{4}$ in accordance with the Bologna Process.

The main consequence of the new degree programmes based on the AngloAmerican B.A., M.A. and Ph.D. system was the splitting up of larger units (1 or 2 semesters) into smaller units of three courses per semester, each with its own study plan, reading list and exam. For instance, the two-semester first year of Documentation Studies, where large parts of the second semester were used for the student's own research project with an appointed supervisor, was converted into six separate courses with six small exams. Even though the units still reflected the complementary structure of Documentation Studies, it has become more difficult for the students to study one document in a complementary way because of the new teaching and examining structure. The only remaining project is the Bachelor's thesis written during the last semester of the Bachelor's degree, often based on a project developed during a 6- to 8-week internship at a library or other document institution.

At the same time as Norway implemented the Bologna Declaration, the Norwegian government introduced a new way of financing higher education in Norway. The

\footnotetext{
${ }^{4}$ According the Bologna Process, all European universities were to standardise their educational programmes to consist of a Bachelor's degree (3 years) + Master's degree (2 years) + Ph.D. (3 years). Before this, the Norwegian undergraduate programme in the Humanities and Social Sciences was one year longer (4 years).
} 
number of students enrolled and - even more importantly - passing the exams and 'producing' study points became important for the amount of funding the institutions received. This also led universities to go to greater effort to promote their degree programmes to potential new students.

In 2006, Documentation Studies decided to create a new Master's programme with one branch of study qualifying graduates for the ALM field. ${ }^{5}$ The idea was to enrol students with different Bachelor's degrees on a Master's degree where they could combine their existing knowledge with qualifications needed in the ALM field, qualifying them to work in academic libraries. While this is the normal way to educate librarians at US universities, the Norwegian system normally requires the student to have a Bachelor's degree in the same subject as the Master's degree. It took several years of debate for this new way of educating librarians to be established. It was a challenge to convince the university and the professional field that this way to educate librarians would ensure candidates with a 'double' qualification who were both librarians and specialists in one or more academic fields. The first students with Bachelor's degrees other than in Documentation Studies were enrolled in 2010, but in 2014 the university already decided to close down the degree because of an evaluation of the Norwegian Agency for Quality Assurance in Education (NOKUT). This evaluation made several important comments, but the most important concerned the qualifications needed to be able to be a student at Master's level. As a consequence, we established a new Master's degree for students holding a Bachelor's degree in Media and Documentation Studies or an equivalent degree course.

The change in name - from Documentation Studies to Media and Documentation Studies - was already decided in 2012, when the Bachelor's degree was changed to Media and Documentation Studies. The first students on this new Bachelor's degree were enrolled in the autumn of 2013, and the first students on the new Master's degree were admitted in 2016. What is new and different about Media and Documentation Studies compared to the 'old' Documentation Studies?

As pointed out by Niels W. Lund, the primary focus in most library education programmes before 1996 was on books and printed documents. Other media formats such as film and audio were not included and the new digital media were only just beginning. The document perspective included the material dimension and therefore also the aspect of media format, for instance focusing on remediation and its consequences for both producers and users. In the first years of Documentation Studies, many student projects were already interested in comparing different media, such as a novel and its film adaptation, or the digitised versions of printed books. Media

\footnotetext{
${ }^{5}$ The existence of a national authority for archives, libraries and museums (ABM-utvikling in Norwegian) between 2003 and 2010 encouraged the perception of similarities between the different sectors. There were similar developments in other European countries at that time, for instance in the UK where The Museum, Libraries and Archives Council (MLA) was launched in 2000. The MLA was abolished by the British government in 2012. See Warren and Matthews (2018), p. 5.
} 
that were new at the time, like CD-ROMs, floppy discs, and homepages, were also studied.

Today, computer games, films and digital media in general constitute subjects for study, as the focus lies on multimedia documents. We are still trying to put the complementary concept into practice, and both practical student activities and internships are included in the new degree programmes. The students have the opportunity to base their Bachelor's and Master's theses on projects developed during their internship at a document institution. Oral exams have been reintroduced in several courses.

Despite the fact that the degree programme's new name was supposed to recruit new students interested in media, a majority of our students still want to become librarians. This is of course due to the situation on the job market where many of the traditional mass media institutions, like the press or television and radio, no longer require as many new employees due to new technologies in both production and consumption. At the same time, the course's popularity with future librarians is a recognition of the fact that ALM institutions are media institutions, and that for instance a librarian needs to have knowledge of different types of media.

Nevertheless, we can conclude that the Troms $\varnothing$ programme was innovative and strategically important not only at the time of its launch in 1996, but remains so today. More than 20 years later, students are recruited to a programme that still includes some components from its early years, such as student-driven activities and the possibility to choose an object to study from a large range of documents. Last but not least, the Troms $\varnothing$ programme has provided many libraries and archives in Northern Norway with qualified candidates.

\section{References}

Geistweidt, J.E., \& Lund, N.W. (2015). The World Opera: A New Global Format for the Business of Opera. In: Belina-Johnson, A., \& Scott, D.B. (eds.), The Business of Opera. London and New York: Routledge, pp. 103-118.

Lund, N.W. (2004). Documentation in a Complementary Perspective. In: Boyd, R.W. (ed.), Aware and Responsible: Papers of the Nordic-International Colloquium on Social and Cultural Awareness and Responsibility in Library, Information and Documentation Studies (SCARLID). Lanham, Md.: Scarecrow Press, pp. 93-102.

Lund, N.W. (2007). Building a Discipline, Creating a Profession: An Essay on the Childhood of 'Dokvit'. In: Skare, R., Lund, N.W., \& Vårheim, A. (eds.), A Document (Re)turn. Contributions from a Research Field in Transition. Frankfurt am Main et al.: Peter Lang, 11-26.

Lund, N.W., \& Buckland, M. (2008). Document, documentation, and the Document Academy: introduction. Archival Science 8, 161-164. https://doi.org/10.1007/s10502-009-9076-3.

Lund, N.W. (2010). Document, text and medium: concepts, theories and disciplines. Journal of Documentation 66(5), 734-749. https://doi.org/10.1108/00220411011066817.

Lund, N.W. (2016). How It All Started: 1996, the First Year of Dokvit. Proceedings from the Document Academy 3:1, article 2. Available at: https://ideaexchange.uakron.edu/docam/vol3/iss1/.

Neo-documentation Around the World: Rethinking Boundaries (2016). Ed. by Gorichanaz, T., Kearns, J., Latham, K.F., \& Skare, R. Special Issue of the Proceedings from the Document Academy 3:1. Available at: https://ideaexchange.uakron.edu/docam/vol3/iss1/.

Olsen, B.I., Lund, N.W., Ellingsen, G., \& Hartwigsen, G. (2012). Document theory for the design of socio- 
technical systems: A document model as ontology of human expression. Journal of Documentation 68(1), 100-126. https://doi.org/10.1108/00220411211200347.

Skare, R., Lund, N.W., \& Vårheim, A. (eds.) (2007). A Document (Re)turn. Contributions from a Research Field in Transition, Frankfurt am Main: Peter Lang.

Skare, R. (2009). Complementarity - a concept for document analysis? Journal of Documentation 65(5), 834-840. https://doi.org/10.1108/00220410910983137.

Søbstad, T. (2000). Standing tired and distressed: et fors $\phi k$ på å lese (seg tilbake) $i$ Kulturwissenschaftliche Bibliothek Warburg som kollektiv og fleksibel bok. Om fremveksten av et kulturhistorisk klassifikasjonssystem, Troms $\emptyset$ (Hovedoppgave i dokumentasjonsvitenskap).

Warren, E., \& Matthews, G. (2018). Public libraries, museums and physical convergence: Context, issues, opportunities: A literature review Part 1. Journal of Librarianship and Information Science. https://doi.org/10.1177/0961000618769720. 